\title{
Irrigação por gotejamento do tomateiro industrial durante o estádio de frutificação, na região de Cerrado
}

\author{
Waldir A Marouelli ${ }^{1}$; Washington L C Silva ${ }^{2}$ \\ ${ }^{1}$ Embrapa Hortaliças, C. Postal 218, 70359-970 Brasília-DF; '²mbrapa Sede-PqEB s/nº 70770-901 Brasília-DF; E-mail: \\ waldir@cnph.embrapa.br
}

\section{RESUMO}

O estudo teve por objetivo estabelecer critério para o manejo de irrigação por gotejamento durante o estádio de frutificação do tomateiro para processamento, nas condições de cerrado do Brasil Central. Avaliaram-se seis regimes de irrigação, com turnos de rega entre 0,25 e 8 dias. A concentração de frutos maduros na colheita aumentou, enquanto a produção de biomassa e o número de frutos por planta foram reduzidos linearmente com os turnos de rega ao quais as plantas foram submetidas. A produtividade e a massa média de frutos comercializáveis apresentaram resposta quadrática aos tratamentos, tendo sido maximizados para um turno de rega de 0,8 dia. O estande final de plantas, a eficiência de uso de água pelas plantas, o teor de sólidos solúveis totais e a firmeza de fruto não foram afetados pelos tratamentos. A incidência de frutos podres apresentou correlação linear negativa com o turno de rega, enquanto que a acidez titulável apresentou correlação positiva. Para o manejo de irrigação baseado no status da água no solo, a tensão matricial crítica associada ao turno de rega que maximizou a produtividade, avaliada a 20 $\mathrm{cm}$ de profundidade, antes de cada irrigação, foi de $10 \mathrm{kPa}$.

Palavras-chave: Lycopersicon esculentum, uso da água, estresse hídrico, frequiência de irrigação.

\begin{abstract}
Response of drip-irrigated processing tomatoes to water regimes during crop fructification stage

The response of drip-irrigated processing tomatoes to irrigation frequencies, from 0.25 to 8 days, during fructification stage, was evaluated aiming to establish an irrigation criterion for the "Cerrado" conditions of Central Brazil. The rate of fully-red tomato fruits at harvest increased linearly as irrigation interval increased, while biomass production and number of fruit per plant were linearly reduced. Both marketable fruit yield and average fruits mass showed quadratic responses to treatments, reaching a maximum at irrigation interval of 0.8 day. Plant final stand, plant water use efficiency, total soluble solids content, and fruit firmness were not affected by irrigation interval. Rotten fruit rate featured negative linear correlation with irrigation interval, while the correlation for acidity was positive. For irrigation scheduling purposes based on soil water status, the critical matric tension, related to the irrigation interval that maximized yield, was $10 \mathrm{kPa}$, evaluated at $20 \mathrm{~cm}$ depth.
\end{abstract}

Keywords: Lycopersicon esculentum, water stress, irrigation scheduling, irrigation interval.

\section{(Recebido para publicação em 09 de agosto de 2005; aceito em 24 de agosto de 2006)}

$\mathrm{O}$ sistema de irrigação por gotejamento vem se tornando uma opção economicamente viável para a irrigação do tomateiro para processamento no Brasil. Isso se deve às vantagens que o sistema oferece, como maior produtividade, melhor qualidade de fruto, economia de água e menor incidência de doenças da parte aérea. Comparativamente à aspersão, o gotejamento possibilita ganhos de até $30 \%$ de rendimento e de redução no uso de água, além de reduzir pela metade o uso de fungicidas (Colla et al., 1999; Prieto et al., 1999).

Dentre os estádios de desenvolvimento do tomateiro, o de frutificação é o mais sensível à deficiência de água no solo, onde irrigações inadequadas comprometem marcadamente o rendimento e a qualidade de fruto (Marouelli et al., 1991; Prieto, 1997). Segundo Marouelli et al. (2003), a produtividade de frutos em tomateiro irrigado por gotejamento não foi afetada por tensões de água do solo entre 15 e $70 \mathrm{kPa}$ durante o estádio vegetativo, mas aumentou linearmente com a redução da tensão durante o estádio de frutificação. Tal estudo sugere que maior rendimento poderia ser alcançado para tensões inferiores a $15 \mathrm{kPa}$, ou seja, realizando as irrigações em regime de alta freqüência durante o estádio de frutificação.

Além de envolver custos extras com a aquisição de tensiômetros ou outros tipos de sensores, a adoção de critérios para fins de manejo de irrigação com base no controle da tensão de água no solo envolve a realização de irrigações com intervalos variáveis, o que é inconveniente para a maioria dos agricultores, principalmente para condições que requerem irrigações muito freqüentes. Para tais condições, é mais oportuno adotar turnos de rega fixos, visto que as práticas culturais e demais tarefas existentes na propriedade podem ser previamente planejadas. No entanto, recomendações para o manejo de água com base em turno de rega devem ser determinadas para condições específicas de clima e solo (Prieto et al., 1999).

O objetivo do estudo foi avaliar a resposta do tomateiro para processamento industrial a diferentes regimes de irrigação por gotejamento, nas condições da região de Cerrado do Planalto Central do Brasil, visando estabelecer a freqüência adequada de rega durante o estádio de frutificação, assim como a tensão crítica de água no solo associada a essa freqüência.

\section{MATERIAL E MÉTODOS}

O estudo foi conduzido no campo experimental da Embrapa Hortaliças, DF, latitude $15^{\circ} 56^{\prime} \mathrm{S}$, longitude $48^{\circ} 08^{\prime} \mathrm{W}$ 
e altitude de $997 \mathrm{~m}$. O clima, segundo classificação de Köppen, é do tipo Cwa, tropical de altitude - mesotérmico, com chuvas no verão e seca no inverno. $\mathrm{O}$ solo é do tipo Latossolo Vermelho distrófico, fase cerrado e textura argilosa, com retenção de água (\%vol.), na camada de 0 a $40 \mathrm{~cm}$ e intervalo de tensão $\left(\Psi_{m}\right)$ de 5 a $1500 \mathrm{kPa}$, expressa por:

$$
\theta\left(\Psi_{m}\right)=24,2+14,8 /\left[1+\left(0,055 \times \Psi_{m}\right)^{1,701}\right]^{0,413}
$$

Os tratamentos, aplicados exclusivamente durante o estádio de frutificação, consistiram de seis turnos de rega: 0,25 (quatro irrigações por dia); 0,5 (duas irrigações por dia); $1 ; 2 ; 4$; e 8 dias. $\mathrm{O}$ estádio de frutificação correspondeu ao período entre o início de frutificação (50\% de plantas com pelo menos um fruto) e o início da maturação de frutos (5\% de frutos maduros), ou seja, entre o $31^{\circ} \mathrm{e}$ o $88^{\circ}$ dia após o transplante das mudas.

O transplante das mudas, do híbrido Heinz 9992, foi realizado na segunda semana de maio de 2001, no espaçamento de 30x120 cm, em solo previamente irrigado. As parcelas experimentais, posicionadas dentro de uma área de plantio contínuo, foram de 28,8 $\mathrm{m}^{2}$ (4 fileiras de 6,0 m), tendo sido colhidas as plantas em $5 \mathrm{~m}$ de cada uma das duas linhas centrais.

A adubação foi com $200 \mathrm{~kg}$ de $\mathrm{N}$, $300 \mathrm{~kg}$ de $\mathrm{K}_{2} \mathrm{O}, 600 \mathrm{~kg}$ de $\mathrm{P}_{2} \mathrm{O}_{5}, 160 \mathrm{~kg}$ de $\mathrm{Ca}, 40 \mathrm{~kg}$ de $\mathrm{Mg}, 5 \mathrm{~kg}$ de $\mathrm{Zn}$ e $2 \mathrm{~kg}$ de B por hectare. Das quantidades totais, $15 \%$ do nitrogênio e do potássio, $60 \%$ do cálcio e $100 \%$ dos demais nutrientes foram aplicados em pré-plantio, sendo as quantidades restantes fornecidas semanalmente via fertirrigação, seguindo esquema de parcelamento apresentado em Marouelli \& Silva (2002). Foram utilizadas as seguintes fontes de nutrientes: uréia, nitrato de potássio, de cálcio e duplo potássio, cloreto de potássio e de cálcio, super fosfato simples, sulfato magnésio e de zinco, cal hidratada e bórax.

As irrigações foram realizadas instalando-se uma linha lateral de gotejadores, espaçados de $30 \mathrm{~cm}$ e com vazão de $1,2 \mathrm{~L} \mathrm{~h}^{-1}$, por linha de plantas. Para minimizar a formação de zona de saturação junto ao colo da planta, as la- terais foram posicionadas de 5 a $10 \mathrm{~cm}$ em relação à linha de plantio. $\mathrm{O}$ manejo de água durante os estádios de pegamento de mudas, vegetativo e de maturação foi conforme Marouelli \& Silva (2002), sendo igual para todos os tratamentos.

A lâmina de água aplicada nos tratamentos com turno de rega de 0,25, 0,5 e 1 dia foi computada a partir da evaporação do tanque Classe A e coeficientes de cultura reportados por Marouelli \& Silva (2002). As lâminas de evaporação de água foram obtidas em uma estação meteorológica a cerca de $500 \mathrm{~m}$ da área experimental. Nos demais tratamentos, as lâminas foram determinadas com base no esgotamento de água no solo (Keller \& Bliesner, 1990), considerando $40 \%$ de área molhada e profundidade efetiva de raízes de $40 \mathrm{~cm}$. O teor de água no solo foi determinado pela equação de retenção de água ajustada, a partir das leituras de tensiômetros, nos tratamentos de 2 e 4 dias, e por gravimetria no de 8 dias. Tensiômetros foram instalados (tratamentos de 0,25 a 4 dias) e amostras de solo coletadas (tratamento de 8 dias) em cada parcela a cerca de $10 \mathrm{~cm}$ da planta e do gotejador (LowengartAycicege et al., 1999) e a $20 \mathrm{~cm}$ de profundidade, em plantas distanciadas a 10 $\mathrm{cm}$ do gotejador.

As condições climáticas médias durante o estádio de frutificação do tomateiro foram: temperatura do ar de $22,5^{\circ} \mathrm{C}$; umidade relativa do ar de $55,6 \%$; insolação de 9,1 horas; radiação global de 18,8 $\mathrm{MJ} \mathrm{m}^{-2}$ dia $^{-1}$; velocidade do vento de $1,1 \mathrm{~m} \mathrm{~s}^{-1}$; evaporação do tanque classe A de $6,6 \mathrm{~mm} \mathrm{dia}{ }^{-1}$ (evapotranspiração de referência de 5,3 $\left.\mathrm{mm} \mathrm{dia}^{-1}\right)$. A ocorrência de chuvas foi de $71 \mathrm{~mm}$ antes do início dos tratamentos, de $4 \mathrm{~mm}$ durante o estádio de frutificação e de $113 \mathrm{~mm}$ após o término dos tratamentos.

A colheita dos frutos, em cada tratamento, foi realizada manualmente em uma única operação. Avaliaram-se as variáveis: lâmina de água aplicada, estande final; biomassa; concentração de frutos maduros; produtividade de frutos; eficiência do uso de água, em quilogramas de frutos comercializáveis por metro cúbico de água aplicada via irri- gação (volume líquido); massa média de fruto; número de frutos por planta; frutos podres; acidez titulável; sólidos solúveis totais; e firmeza. A biomassa foi determinada secando-se a parte aérea das plantas a $60^{\circ} \mathrm{C}$, excluindo-se todos os frutos. Para a taxa de concentração de frutos maduros, produtividade, massa média de fruto e número de frutos por planta consideraram-se apenas os maduros, sem danos, independente de tamanho. A acidez titulável, o teor de sólidos solúveis totais e a firmeza de fruto foram determinados segundo Moretti et al. (1998) e Calbo \& Nery (1995), em amostras de quinze frutos.

$\mathrm{O}$ delineamento experimental foi blocos ao acaso, com quatro repetições. Os dados foram submetidos à análise de variância e as variáveis, afetadas pelos tratamentos, analisadas com regressão linear pelo método de polinômios ortogonais. Para tal, usou-se transformação logarítmica dos turnos de rega.

\section{RESULTADOS E DISCUSSÃO}

\section{Uso de água pelas plantas}

A lâmina total líquida de água aplicada via irrigação (Li, mm) ao longo do ciclo fenológico do tomateiro foi reduzida quanto maior o turno de rega (TR, dia) durante o estádio de frutificação, tendo sido a resposta ajustada pela seguinte equação: $\mathrm{Li}=347,7$ - 5,660xTR $0,466 x_{T R}^{2}\left(R^{2}=0,99\right)$. Das lâminas totais aplicadas, $155 \mathrm{~mm}$ foram fornecidos antes e após o estádio de frutificação.

A lâmina de irrigação no tratamento com maior turno de rega $(273 \mathrm{~mm})$ foi $21 \%$ menor que aquela aplicada no tratamento irrigado mais freqüentemente.

A ocorrência de chuvas durante o estádio de frutificação totalizou $4 \mathrm{~mm}$, portanto, não tendo nenhum efeito significativo sobre a resposta do tomateiro aos tratamentos. Segundo Allen et al. (1998), o menor uso de água pelas plantas nos tratamentos irrigados menos freqüentemente deve-se a dois fatores principais: a) menor perda de água por evaporação em razão da superfície do solo permanecer seca por maiores períodos; b) menor transpiração pelas plantas em razão da maior dificuldade 

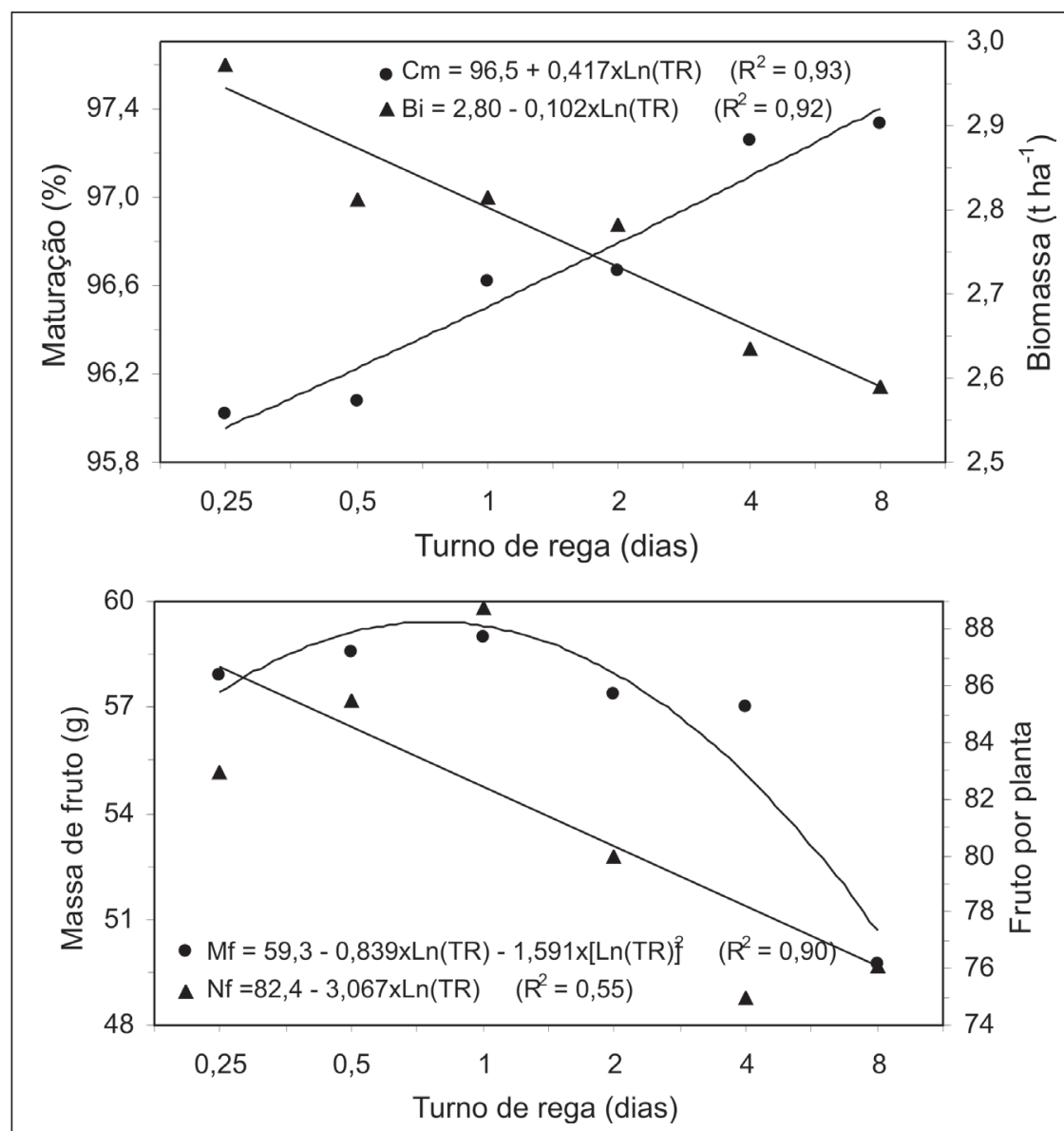

Figura 1. Funções de resposta para concentração de maturação de frutos $(\mathrm{Cm})$, produção de biomassa (Bi), número de frutos por planta (Nf) e massa média de fruto (Mf) conforme o turno de rega durante o estádio de frutificação do tomateiro. Brasília, Embrapa Hortaliças, 2001.

de extração de água pelas raízes acarretada pelo aumento da tensão de retenção de água pelo solo.

A média das tensões máximas de água do solo (Ts, $\mathrm{kPa})$, avaliadas a 20 $\mathrm{cm}$ de profundidade durante o estádio de frutificação, teve resposta positiva ao turno de rega adotado ( $\mathrm{Ts}=$ $3,3+8,594 \times \mathrm{TR}+0,513 \times \mathrm{TR}^{2} ; \mathrm{R}^{2}=0,99$ ). Pela equação ajustada, as tensões nos tratamentos de 0,$25 ; 0,5 ; 1 ; 2 ; 4$ e 8 dias foram, respectivamente, $5,8,12,23,46$ e $105 \mathrm{kPa}$. Verifica-se, portanto, que as plantas, durante o estádio de frutificação, foram submetidas a uma faixa de tensão muito mais ampla que aquela avaliada por Marouelli et al. (2003).

\section{Desenvolvimento de plantas}

As colheitas dos frutos foram realizadas entre 121 e 122 dias após o transplante das mudas. A concentração de maturação de frutos aumentou linear- mente quanto maior o turno de rega adotado (Figura 1). Conforme observado por Prieto et al. (1999), isto significa que plantas submetidas a maiores restrições de água durante o estádio de frutificação tiveram redução no ciclo de desenvolvimento.

O estande final de plantas (média de 2,8 plantas por $\mathrm{m}^{2}$ ) não foi afetado significativamente $(p>0,05)$ pelos tratamentos, indicando que os regimes de irrigação aos quais as plantas foram submetidas não proporcionaram condições diferenciadas para acarretar maior ou menor morte de plantas decorrente a estresse hídrico ou doenças. Resultados semelhantes foram relatados por Marouelli et al. (1991, 2003) para plantas de tomateiro submetidas a tensões de água no solo entre 15 e $460 \mathrm{kPa}$ durante o estádio de frutificação.

A produção de biomassa, avaliada pela massa seca da parte aérea fora os frutos, foi reduzida linearmente com o aumento do intervalo entre irrigação a que as plantas foram submetidas (Figura 1). Plantas submetidas a condições de máximo déficit hídrico (turno de rega de 8 dias) tiveram $13 \%$ de redução na biomassa comparativamente ao tratamento com turno de rega de 0,25 dia. Colla et al. (1999), por outro lado, não observaram variações no crescimento de plantas quando se reduziu a lâmina de água em até $20 \%$ durante todo ciclo do tomateiro. Tais divergências devem-se, principalmente, ao fato de que no presente estudo as plantas foram submetidas a um maior déficit de água, com redução de $38 \%$ da lâmina aplicada durante o estádio de frutificação.

\section{Produção de frutos}

O número de frutos comercializáveis por planta, que é um dos principais componentes de produção de tomateiro, foi reduzido linearmente com o aumento do intervalo entre irrigações (Figura 1). Esta redução pode ser explicada pelo menor crescimento das plantas, maior queda de flores e abortamento de frutos em plantas submetidas a condições de maior déficit de água durante o final da fase de florescimento e início de frutificação (Marouelli et al., 1991; Prieto, 1997).

Maior massa média de frutos comercializáveis foi obtida para um turno de rega de 0,8 dia (Figura 1). Aparentemente, este resultado diverge do obtido por Marouelli et al. (2003), que não verificaram diferenças significativas para tensões de água no solo entre 15 e $70 \mathrm{kPa}$. Tais diferenças podem ser explicadas pelo fato de que no presente estudo as plantas foram submetidas a uma maior amplitude de tensões ( 5 a 105 $\mathrm{kPa}$ ). Redução da massa de fruto, mesmo em plantas submetidas a condições moderadas de deficiência de água no solo durante o estádio de frutificação, foi constatada por Colla et al. (1999) em concordância com o presente estudo. Já condições de alta umidade no solo no tratamento irrigado quatro vezes por dia podem ter prejudicado a aeração na rizosfera e favorecido a lixiviação de nutrientes, principalmente de nitrogênio, tendo contribuído, assim, para reduzir o tamanho dos frutos. 
A produtividade de frutos comercializáveis apresentou resposta quadrática com os tratamentos (Figura 2), tendo sido maximizada para um turno de rega de 0,8 dia. Com base nos componentes de produção avaliados, verifica-se que as diferenças de produtividade observadas foram devidas tanto ao número de frutos por planta quanto à massa dos frutos, haja vista que o estande de plantas não foi influenciado pelos diferentes regimes de irrigação. Pela equação de regressão ajustada para tensão de água solo em função de turno de rega, obtém-se que a tensão crítica associada ao turno de rega de 0,8 dia, que maximizou a produtividade de frutos, foi de $10 \mathrm{kPa}$. Esse resultado vem complementar o trabalho realizado por Marouelli et al. (2003), que indicava que a realização de irrigações visando manter a tensão máxima de água no solo abaixo de $15 \mathrm{kPa}$ poderia ser capaz de acarretar incrementos de produtividade de frutos em tomateiro irrigado por gotejamento.

A eficiência de uso de água pelas plantas (média de 39,4 $\mathrm{kg} \mathrm{m}^{-3}$ ) não foi afetada pelos diferentes regimes de irrigação a que as plantas foram submetidas durante o estádio de frutificação, similarmente ao observado por Marouelli et al. (2003). Isto indica que sob condições onde a água é fator limitante, deve-se manejar a irrigação visando maximizar a produtividade de frutos e reduzir a área plantada, de forma a tornar mínimo o custo de produção por unidade de água utilizada. Valores máximos de eficiência do uso de água reportados na literatura, para tomateiro irrigado por gotejamento, variam de 31,0 a 42,6 kg.m ${ }^{-3}$ (Phene et al., 1992; Lowengart-Aycicege et al., 1999).

\section{Qualidade de fruto}

A incidência de frutos com podridão apical (média de 0,2\%), o teor de sólidos solúveis totais (média de 5,1\%) e a firmeza de fruto (média de $0,329 \mathrm{kgf} \mathrm{cm}^{-2}$ ) não foram afetados significativamente ( $\mathrm{p}>0,05)$ pelos tratamentos.

A diminuta ocorrência de podridão apical deveu-se ao adequado suprimento de cálcio à cultura, parte fornecida via fertirrigação a partir da floração do tomateiro, e ao fato das plantas não terem sido submetidas a condições extremas de déficit de água no solo (Hochmuth, 1997), ou seja, a tensão


Figura 2. Funções de resposta para produtividade comercializável de frutos $(\mathrm{Pc})$, taxa de frutos podre (Fp) e ácido cítrico (\%) conforme o turno de rega durante o estádio de frutificação do tomateiro. Brasília, Embrapa Hortaliças, 2001.

média de água no solo não ultrapassou $105 \mathrm{kPa}$.

Efeito não significativo sobre o teor de sólidos solúveis em tomateiro submetido a diferentes regimes de irrigação durante o estádio de frutificação também foi observado por Marouelli et al. (1991) e Colla et al. (1999). Segundo Lowengart-Aycicege et al. (1999), o regime hídrico adotado durante o estádio de frutificação tem pequeno efeito sobre teor de sólidos solúveis de frutos, mas é decisivo durante o estádio de maturação do tomateiro.

A incidência de frutos podres apresentou resposta linear negativa com o turno de rega adotado (Figura 2). O maior apodrecimento de frutos nos tratamentos irrigados em regime de alta freqüência deve-se, basicamente, ao maior tempo de contado de frutos com a superfície molhada do solo e ao maior crescimento vegetativo da parte aérea, criando um ambiente mais úmido dentro do dossel de plantas (Rotem \& Palti,
1969). Sob tais condições, várias doenças fúngicas e bacterianas, como a rizoctoniose e podridão-mole, podem ter ocorrido principalmente nos frutos em contato direto com o solo e naqueles com ferimentos causados por insetos (Lopes et al., 2000).

Similarmente ao observado por Colla et al. (1999), verificou-se resposta linear positiva da acidez titulável com o turno de rega (Figura 2). Assim, plantas submetidas a restrições hídricas produziram frutos mais ácidos que aquelas irrigadas em regime de mais alta freqüência durante o estádio de frutificação.

\section{AGRADECIMENTOS}

Os autores agradecem à Rain Bird do Brasil Ltda., pela doação de parte do sistema de irrigação, e à Unilever BestFoods do Brasil Ltda., pelo fornecimento das mudas de tomateiro. 


\section{REFERÊNCIAS}

ALLEN RG; PEREIRA LS; RAES D; SMITH M 1998. Crop evapotranspiration: guidelines for computing crop water requirements. Roma: FAO 328p. (Irrigation and Drainage Papers, 56).

CALBO AG; NERY AA. 1995. Medida de firmeza em hortaliças pela técnica de aplanação. Horticultura Brasileira 13: 14-185.

COLLA G; CASA R; LO CASCIO B SACCARDO F; LEOMI C. 1999. Responses of processing tomato to water regime and fertilization in Central Italy. Acta Horticulturae 487: 531-535.

HOCHMUTH GJ. 1997. Tomato fertilizer management. In: FLORIDA TOMATO INSTITUTE 1997; Naples FL. Proceedings.. Naples: University of Florida/Citrus \& Vegetable Magazine. p. 68-72.

KELLER J; BLIESNER RD. 1990. Sprinkler and trickle irrigation. New York: VanNostrand Reinhold. 652p.
LOPES CA; SANTOS JR; ÁVILA AC; BEZERRAIC; CHARCHAR JM; QUEZADO-DUVAL AM. 2000. Doenças: identificação e controle. In: SILVA JBC; GIORDANO LB (eds). Tomate para processamento industrial. Brasília: Embrapa Comunicação para Transferência de Tecnologia: Embrapa Hortaliças. p. 88-111.

LOWENGART-AYCICEGI A; MANOR H; KRIEGER R; GERA G. 1999. Effects of irrigation scheduling on drip-irrigated processing tomatoes. Acta Horticulturae 487: 513-518.

MAROUELLI WA; SILVA HR; OLIVEIRA CAS. 1991. Produção de tomate industrial sob diferentes regimes de umidade no solo. Pesquisa Agropecuária Brasileira 26: 1531-1537.

MAROUELLI WA; SILVA WLC. 2002. Tomateiro para processamento industrial: irrigação e fertirrigação por gotejamento. Brasília: Embrapa Hortaliças. 32p. (Embrapa Hortaliças. Circular Técnica, 30).

MAROUELLI WA; SILVA WLC; MORETTI CL. 2003. Resposta do tomateiro para processamento a tensões de água no solo, sob irrigação por gotejamento. Engenharia Agrícola 23: 1-8.
MORETTI CL, SARGENT SA, HUBER DJ, CALBO AG, PUSCHMANN R. 1998. Chemical composition and physical properties of pericarp, locule and placental tissues of tomatoes with internal bruising. Journal of the American Society for Horticultural Science 123: 656-660.

PHENE CJ, HUTMACKER RB, DAVIS KR. 1992. Two hundred tons per hectare of processing tomatoes - Can we reach it? HortTechnology 2: 16-22.

PRIETO MH. 1997. Deficit irrigation treatments in processing tomato under surface irrigation In: INTERNATIONAL CONFERENCE ON THE PROCESSING TOMATO, 1. Proceedings... Alexandria: ASHS/IPA. p. 48-53.

PRIETO MH; LÓPEZ J; BALLESTEROS R. 1999. Influence of irrigation system and strategy of the agronomic and quality parameters of the processing tomatoes in Extremadura. Acta Horticulturae 487: 575-579.

ROTEM J; PALTI J. 1969. Irrigation and plant diseases. Annual Review of Phytopathology 7 : 267-288. 